\title{
The design and testing issues of radiation tolerant microwave amplifiers implemented in the domestic GaAs pHEMT $0.5 \mu \mathrm{m}$ process
}

\author{
Denis Sotskov ${ }^{1,2, *}$, Alexander Kuznetsov ${ }^{1,2}$, Nikolay Usachev ${ }^{1,2}$, Vadim Elesin $^{1,2}$, \\ and Ilya Selishchev ${ }^{1}$ \\ ${ }^{1}$ National Research Nuclear University MEPhI (Moscow Engineering Physics Institute), 115409, \\ Moscow, Kashirskoe shosse 31, Russian Federation \\ ${ }^{2}$ Specialized Electronic Systems, 115409, Moscow, Kashirskoe shosse 31, Russian Federation
}

\begin{abstract}
The investigation results of the possibility of manufacturing radiation tolerant microwave amplifiers implementing in domestic GaAs D-mode pHEMT $0.5 \mu \mathrm{m}$ process are presented in this work. The amplifier with an operating frequency range from $0.1 \mathrm{GHz}$ to $3.5 \mathrm{GHz}$, gain above $15 \mathrm{~dB}$, noise figure below $2.2 \mathrm{~dB}$, output linearity above $17 \mathrm{dBm}$ is designed, produced and measured. The characteristic property of the amplifier is a single positive supply voltage and extended frequency range up to $100 \mathrm{MHz}$ provided by the external capacitor circuit. Transient radiation effects in the amplifier are investigated up to the dose rate value of $4.9 \cdot 10^{9}$ a.u./s. The recovery time does not exceed $4 \mu$ s according to the experimental results.
\end{abstract}

\section{Introduction}

Microwave amplifier integrated circuits (IC) implemented in GaAs pseudo high-electron mobility transistor (pHEMT) processes are widely used in main radio-frequency wireless systems for industrial, space and science applications because its wide operating frequency range, high amplification (gain), low noise figure (NF), high output power [1]. Traditionally, amplifiers ICs are implemented in the depletion mode (D-mode) pHEMT process, which required additional bias circuits and negative voltage supply for biasing [1,2].

Enhancement mode (E-mode) pHEMT processes are becoming increasingly popular for various microwave amplifier implementation due to the following advantages: high efficiency, high transconductance, gain, cut-off frequency $(\mathrm{Ft})$ and maximum oscillation frequency (Fmax), no negative voltage requirement, compatibility with D-mode pHEMT process (E/D-mode pHEMT process) [3]. Meanwhile, the conventional low cost and widely available D-mode pHEMT process can also be used to design high performance microwave amplifiers even with single positive supply operation [4].

The purpose of this work is to show the applicability of the domestic GaAs D-mode pHEMT $0.5 \mu \mathrm{m}$ process in the implementation of the radiation tolerant microwave amplifiers with the operating frequency range from $0.1 \mathrm{GHz}$ to $3.5 \mathrm{GHz}$, gain above $15 \mathrm{~dB}$,

* Corresponding author: disot@spels.ru 
NF below $2.2 \mathrm{~dB}$, output linearity above $17 \mathrm{dBm}$ and single positive supply voltage operation. The comparison results of the proposed amplifier characteristics with those for its analog TGA5108 (TriQuint Semiconductor) [5] implemented in GaAs E/D-mode pHEMT $0.5 \mu \mathrm{m}$ process [6] are also presented.

\section{GaAs pHEMT $0.5 \mu \mathrm{m}$ process}

The domestic GaAs D-mode pHEMT $0.5 \mu \mathrm{m}$ process with Ft up to $35 \mathrm{GHz}$ and minimal NF (NFmin) of $1.2 \mathrm{~dB}$ at $8 \mathrm{GHz}$ [7] has been used for the amplifier implementation. According to the results provided in [8], the presented GaAs D-mode pHEMT $0.5 \mu \mathrm{m}$ process allows producing a microwave amplifier with immunity to the total ionizing dose and the destructive single event effects up to $300 \mathrm{krad}$ and $60 \mathrm{MeV} \cdot \mathrm{cm}^{2} / \mathrm{mg}$ respectively. Meanwhile, transient radiation effects should be investigated in this work [9].

TGA5108 implemented in the «TQPED» E/D-mode pHEMT $0.5 \mu \mathrm{m}$ process (TriQuint Semiconductor) that has $\mathrm{Ft}$ of $30 / 25 \mathrm{GHz}$ [6]. The main process parameters for both amplifiers are summarized in Table 1.

Table 1. GaAs pHEMT $0.5 \mu \mathrm{m}$ process parameters.

\begin{tabular}{|c|c|c|c|}
\hline Process & $\begin{array}{c}\text { Domestic } \\
\text { D-mode } \\
\mathbf{0 . 5} \boldsymbol{\mu m}\end{array}$ & $\begin{array}{c}\text { «TQPED» E/D-mode 0.5 } \\
\boldsymbol{\mu} \text { (T) (TriQuint } \\
\text { Semiconductor) [6] }\end{array}$ \\
\hline Transistor type & D-mode & D-mode & E-mode \\
\hline $\begin{array}{c}\text { Pinch-off voltage (D-mode) / } \\
\text { Threshold voltage (E-mode), V }\end{array}$ & -1.55 & -0.8 & 0.35 \\
\hline Transconductance, mS/mm & 350 & 350 & 625 \\
\hline Cut-off frequency, GHz & 35 & 25 & 30 \\
\hline Minimum noise figure, dB & $1.2 @ 8 \mathrm{GHz}$ & - & - \\
\hline Metal layers & 2 & \multicolumn{2}{|c|}{3} \\
\hline
\end{tabular}

\section{Amplifier circuit}

A simplified schematic of the proposed amplifier is shown in Fig. 1. The main features of this amplifier are: (1) wideband operation due to the use of cascode configuration with resistive parallel feedback (resistor R1); (2) single positive supply mode operation due to the use of self-bias circuit (resistor R3, capacitor C2); (3) external (connect to pad "C") capacitors can be used to improve amplifier performance at frequencies below $0.5 \mathrm{GHz}$.

TGA5108 is implemented based on E-mode pHEMT and has a cascode configuration with resistive parallel feedback without a self-bias circuit.

\section{Amplifier performances}

The measurements of the amplifier proposed in the paper were performed on the wafer using Cascade semi-automated probe station, vector network analyzer (VNA) and signal (spectrum) analyzer with noise figure measurement option. The experimental setup used for amplifier dies testing is shown in Fig. 2. The measurement results of TGA5108 are presented in [5] (TGA5108 has been tested using the evaluation board). 


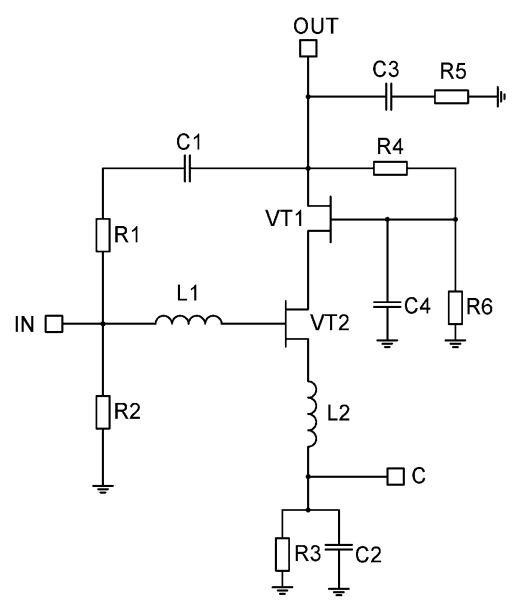

Fig. 1. Simplified circuit of the proposed amplifier.

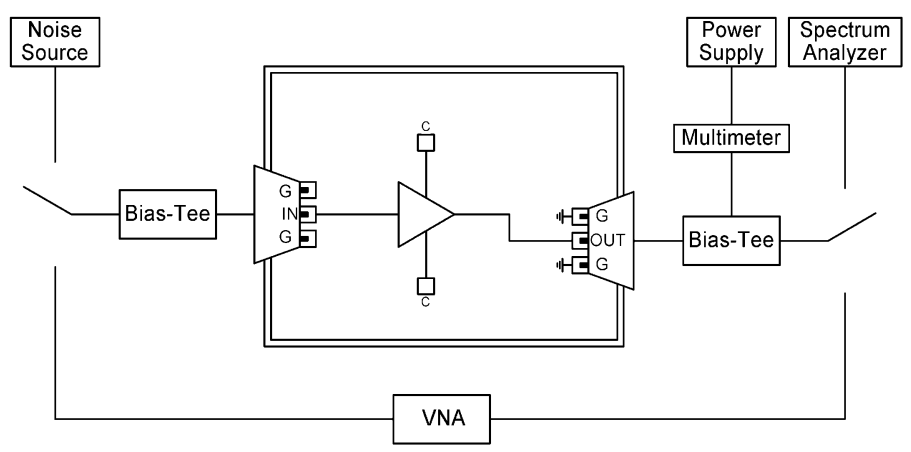

Fig. 2. Experimental setup for amplifier performance measurements.

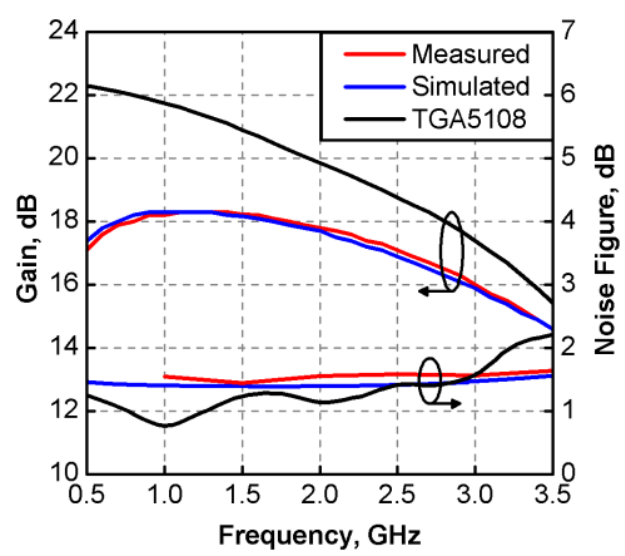

a)

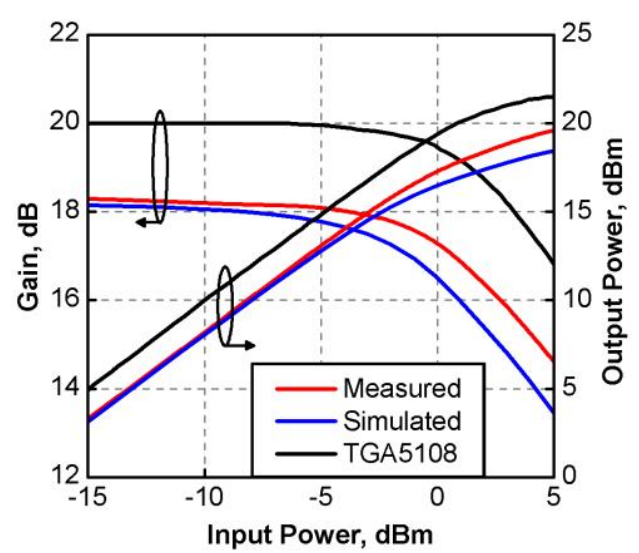

b)

Fig. 3. Frequency dependence of the gain and noise figure (a) and gain and output power versus input power (b) for the proposed amplifier and TGA5108.

The simulated and measured results of the proposed amplifier and measured TGA5108 characteristics are shown in Fig. 3. The proposed amplifier has similar to TGA5108 noise and linearity performance, however smaller (1...4 dB less) small-signal gain due to less 
transconductance of the D-mode pHEMT and/or other feedback factor. Meanwhile, TGA5108 has significant $(7 \mathrm{~dB})$ gain flatness due to the impact of the evaluation board and/or other feedback factor.

To provide measurements of the proposed amplifier performance in the low-frequency range (with and without external capacitors) and the temperature range from $-60{ }^{\circ} \mathrm{C}$ to $+125^{\circ} \mathrm{C}$, a special measurement test fixture has been designed and implemented (see Fig. 4).

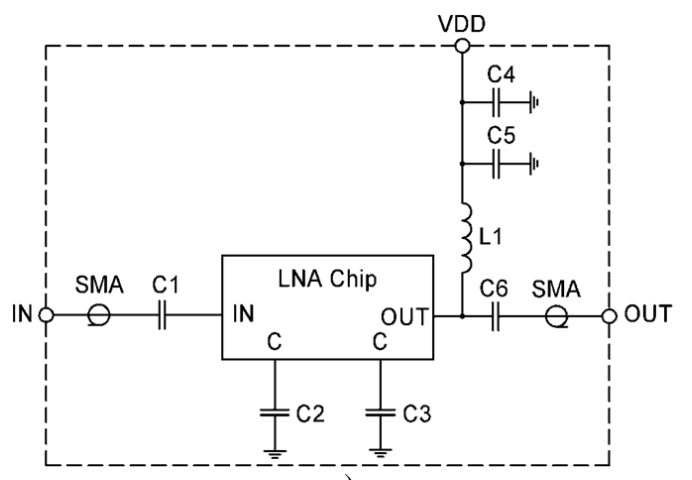

a)

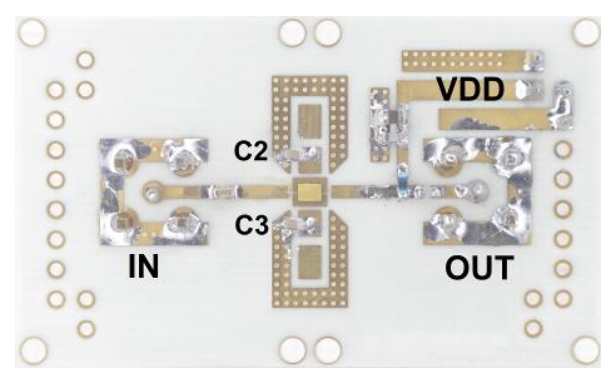

b)

Fig. 4. Special measurement test fixture schematic (a), photograph (b).

The measured low-frequency performance of the amplifier with and without mounted $1 \mathrm{nF}$ SMD capacitors C2 and C3 are shown in Fig. 5. The dependencies are shown in Fig. 5 demonstrate that the gain and noise figure have been improved by more than $10 \mathrm{~dB}$ and $5 \mathrm{~dB}$, respectively, at $100 \mathrm{MHz}$ through using the external capacitors.

The measurement results of the proposed amplifier parameters in the ambient temperature range from $-60{ }^{\circ} \mathrm{C}$ to $+125{ }^{\circ} \mathrm{C}$ and frequency range from $0.5 \mathrm{GHz}$ to $3.5 \mathrm{GHz}$ are shown in Fig. 6 . The gain value monotonically decreases as the ambient temperature increases, and the gain change does not exceed $2 \mathrm{~dB}$. The noise figure monotonically increases with the increase of the ambient temperature, the variation of the noise figure does not exceed $1.3 \mathrm{~dB}$. The output linearity (output $\mathrm{P}_{1 \mathrm{~dB}}$ ) monotonically decreases with the increase of the ambient temperature, the output $\mathrm{P}_{1 \mathrm{~dB}}$ shift in the temperature range is not higher than $1.5 \ldots 2 \mathrm{~dB}$. The change in the current consumption in the considered ambient temperature range does not exceed $3.8 \mathrm{~mA}$. The measured performance of the presented amplifier is summarized in Table 2 along with its counterpart from TriQuint Semiconductor.

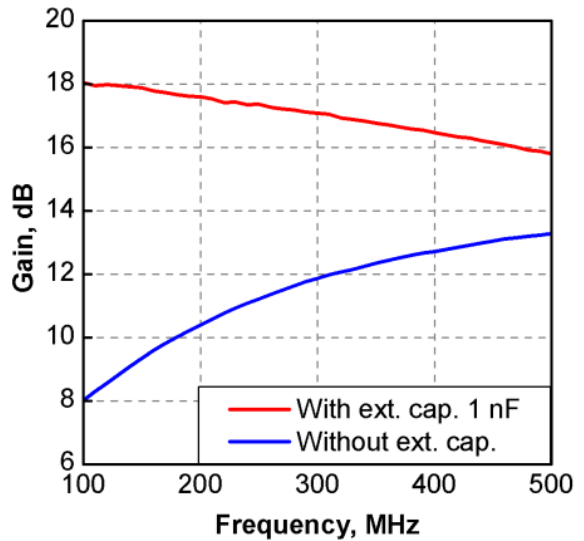

a)

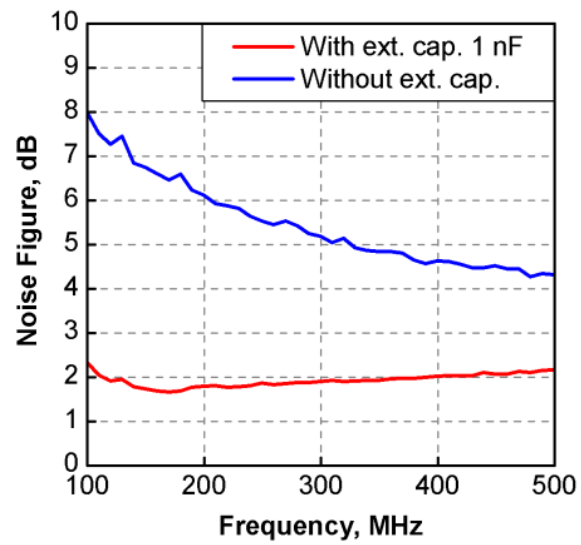

b)

Fig. 5. Measured gain (a) and noise figure (b) versus frequency for the proposed amplifier. 


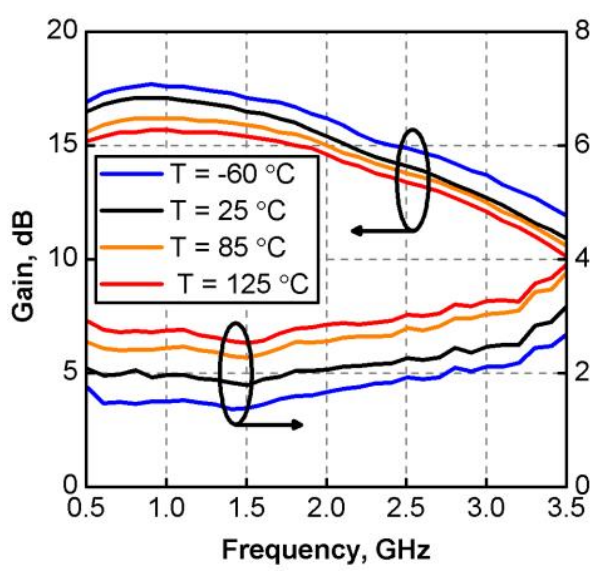

a)

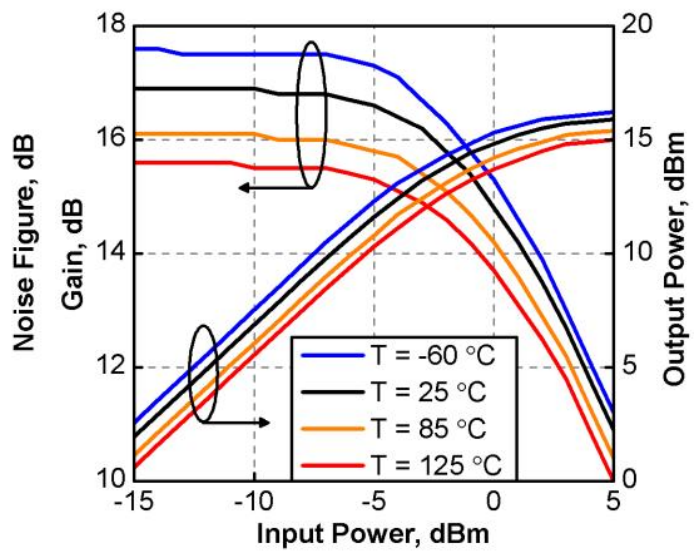

b)

Fig. 6. Measured gain and noise figure versus frequency (a) and gain and output power versus input power (b) for the proposed amplifier in the ambient temperature range from $-60{ }^{\circ} \mathrm{C}$ to $+125^{\circ} \mathrm{C}$.

Table 2. Measured performance summary of the proposed amplifier and its counterpart $\left(\mathrm{T}=25{ }^{\circ} \mathrm{C}\right)$.

\begin{tabular}{|c|c|c|}
\hline Microwave Amplifier & This Work & TGA5108 \\
\hline Process & $\begin{array}{c}0.5 \mu \mathrm{m} \\
\text { D-pHEMT }\end{array}$ & $\begin{array}{c}0.5 \mu \mathrm{m} \\
\text { E/D-pHEMT }\end{array}$ \\
\hline Operating frequency, $\mathrm{GHz}$ & $0.5(0.1) \ldots 3.5$ & $0.5 \ldots 3.5$ \\
\hline Gain, $\mathrm{dB}$ & 15.3 & 15 \\
\hline Gain flatness, $\mathrm{dB}$ & 4 & 7 \\
\hline Noise figure, $\mathrm{dB}$ & 2.2 & 2.2 \\
\hline Output $\mathrm{P}_{1 \mathrm{~dB}}, \mathrm{dBm}$ & 17 & 20 \\
\hline Gain temperature coefficient, $\mathrm{dB} /{ }^{\circ} \mathrm{C}$ & -0.011 & -0.011 \\
\hline Noise figure temperature coefficient, $\mathrm{dB} /{ }^{\circ} \mathrm{C}$ & 0.007 & 0.005 \\
\hline Power consumption, $\mathrm{mW}$ & 325 & 425 \\
\hline Chip size, $\mathrm{mm}^{2}$ & $2.15 \times 1.65$ & $1.49 \times 0.85$ \\
\hline
\end{tabular}

The investigation of transient radiation effects in the proposed amplifier has been performed in SPELS and MEPhI test center [10-12] at the dose rate (P) value from $6 \cdot 10^{6}$ a.u./s to $4,9 \cdot 10^{9}$ a.u./s. The amplifier gain at the frequency of $1.5 \mathrm{GHz}$ has been controlled during irradiation. Waveforms of the amplifier gain ionizing response under irradiation at three different $P$ values are shown in Fig. 7. It has been determined that the recovery time (limit: the gain decreases by $1 \mathrm{~dB}$ or more) does not exceed $4 \mu \mathrm{s}$. The dependence of the gain response amplitude on $\mathrm{P}$ value is shown in Fig. 8. The figure shows that the gain monotonically decreases with the increase of $\mathrm{P}$ value.

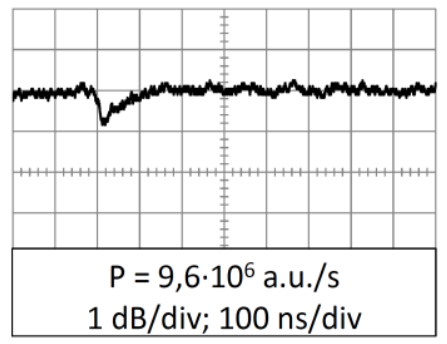

a)

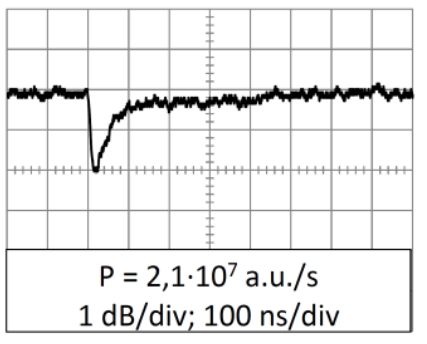

b)

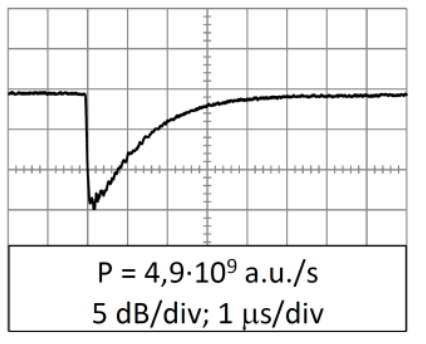

c)

Fig. 7. Waveforms of the gain ionizing response under irradiation at three $P$ values:

9.6 $10^{6}$ a.u./s (a); $2.1 \cdot 10^{7}$ a.u./s (b); $4.9 \cdot 10^{9}$ a.u./s (c). 


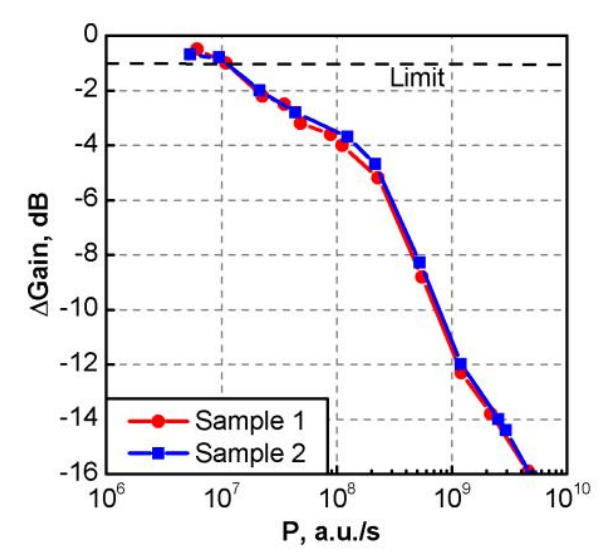

Fig. 8. The dependence of the gain ionizing response amplitude on $P$ value.

\section{Conclusion}

The investigation results of the possibility of manufacturing radiation tolerant microwave amplifiers implementing in domestic GaAs D-mode pHEMT $0.5 \mu \mathrm{m}$ process are presented. The amplifier with an operating frequency range from $0.1 \mathrm{GHz}$ to $3.5 \mathrm{GHz}$, gain above 15 $\mathrm{dB}$, noise figure below $2.2 \mathrm{~dB}$, output linearity above $17 \mathrm{dBm}$ is designed, produced and measured. The characteristic property of the amplifier is a single positive supply voltage and extended frequency range up to $100 \mathrm{MHz}$ provided by the external capacitor circuit. The amplifier has immunity to total ionizing dose and destructive single event effects up to $300 \mathrm{krad}$ and $60 \mathrm{MeV} \cdot \mathrm{cm}^{2} / \mathrm{mg}$, respectively, and has not long-term radiation effects. The obtained in this work results confirms the applicability of the conventional low cost and widely available D-mode pHEMT process in high performance radiation tolerant microwave amplifiers implementation.

\section{Acknowledgement}

This work has been conducted in accordance with the agreement between the Ministry of Education and Science of the Russian Federation and National Research Nuclear University MEPhI № 8.2373.2017/4.6.

\section{References}

1. G. Gonzalez, Microwave Transistor Amplifiers: Analysis and Design (Pearson, London, 1996)

2. R. L. Ross, S. P. Svensson, P. Lugli, Pseudomorphic HEMT Technology and Applications (Kluwer Academic Publishers, 1996)

3. Y. Tkachenko, C. Wei, Y. Zhao, A. Klimashov, D. Bartle, Electrochemical Society Proceedings, 2000-1, 110 (2000)

4. B. S. Virdee, B. Y. Banyamin, A. S. Virdee, Broadband Microwave Amplifiers (Artech House Publishers, Norwood, 2004)

5. Datasheet TGA5108 URL: https://www.qorvo.com/products/p/TGA5108\#documents

6. Datasheet TQPED URL: https://www.digchip.com/datasheets/ download_datasheet.php?id= 1821412\&part-number=TQPED

7. O.R. Fazylkhanov, I.S. Pushnitsa, S.I. Strelnikov, M.A. Kalyakin, A.H. Filaretov, 2017 27th International Crimean Conference Microwave \& Telecommunication Technology, 143 (2017) 
8. D. I. Sotskov, N. A. Usachev, V. V. Elesin, A. G. Kuznetsov, K. M. Amburkin, G. V. Chukov, M. I. Titova, N. M. Zidkov, 31th International Conference on Microelectronics (2019), (to be published)

9. V. V. Elesin, Russian Microelectronics 43, 139 (2014)

10. O. A. Kalashnikov, P. V. Nekrasov, A. Y. Nikiforov, V. A. Telets, G. V. Chukov, V. V. Elesin, Russian Microelectronics 45, 33 (2016)

11. N. A. Usachev, V.V. Elesin, A. Y. Nikiforov, V. A. Telets, 29th International Conference on Microelectronics, 405 (2014)

12. V. V. Elesin, G. N. Nazarova, N. A. Usachev, Russian Microelectronics 39, 134 (2010) 